\title{
Kepemimpinan Terhadap Kinerja Karyawan yang dimediasi Budaya Organisasi dan Komitmen
}

\author{
Leadership on Employee Performance mediated by Organizational \\ Culture and Commitment
}

Oleh:
Ristianti Ratna Aprilia1; Saepunajat Japarudin²; Taufiq Rachman ${ }^{3}$
Program Studi Magister Manajemen ${ }^{12}$

khaylarahman12@gmail.com¹; saepunajatjaparudin@gmail.com²; tfaman@gmail.com³

\begin{abstract}
ABSTRAK
Tujuan penelitian untuk menguji model penelitian yang menyatakan bahwa kepemimpinan mampu mempengaruhi kinerja karyawan yang diintervening oleh budaya organisasi dan komitmen. Penelitian menggunakan 50 orang karyawan sebagai sample penelitian. Analisis data menggunakan SmartPLS dengan pendekatan model struktural. Penelitian menunjukkan komitmen memediasi kepemimpinan terhadap kinerja tetapi budaya organisasi tidak sebagai pemediasi.
\end{abstract}

Kata kunci: kepemimpinan; budaya organisasi; komitmen; kinerja

\begin{abstract}
The purpose of the study is to test a research model that states that leadership is able to influence the performance of employees who are intervening by organizational culture and commitment. The study used 50 employees as a research sample. Data analysis using SmartPLS with a structural model approach. Research shows a commitment to mediating leadership to performance but organizational culture is not as a mediation.
\end{abstract}

Keywords: leadership; organizational culture; commitment; performance

\section{PENDAHULUAN}

Kinerja perusahaan tergambar dari kinerja karyawan yang merupakan aset terpenting suatu perusahaan. Kinerja karyawan merupakan gambaran kontribusi karyawan kepada organisasi (Mathis \& Jackson, 2012) dalam mencapai tujuan. Untuk itu diperlukan kepemimpinan agar organisasi dapat berjalan dengan baik. Kepemimpinan yang baik dapat meningkatkan semangat kerja karaywan (Pangabean, 2011). Sebaliknya, tidak baiknya kepemimpinan akan menhgkambat keinginan karyawan untuk berkembang (Kartono, 2010).

Kepemimpinan yang baik seharusnya mendorong karyawan bekerja lebih baik. Pemimpin yang melaksanakan kepemimpinan diharapkan dapat mengambil keputusan yang tepat (Poerwaningrum \& Sudirjo, 2016). Namun 
terdapat temuan bahwa kepemimpinan tidak berpengaruh signifikan terhadap kinerja karyawan (Saputri \& Andayani, 2018). Untuk itu perlu dilihat faktor apa saja yang dapat memediasi antara kepemimpinan terhadap kinerja karyawan. Budaya organisasi dan komitmen merupakan dua hal yang berpotensi memediasi kepemimpinan terhadap kinerja.

Budaya organisasi dan komitmen yang tinggi merupakan penyebab meningkatnya kinerja. Kinerja yang baik memerlukan budaya organisasi (Pratama, 2017). Pencapaian kualitas, kuantitas dan ketepatan hasil kerja memerlukan kesungguhan atau komitmen dari para karyawan. Tumbuhnya upaya untuk memberikan yang terbaik membuat karyawan dapat menyelesaikan setiap tugas yang menjadi tanggung jawabnya (Frimayasa \& Lawu, 2020).

$$
\text { Kepemimpinan mempengaruhi }
$$

budaya organisasi secara positif. Semakin baik kepemimpinan semakin baik juga budaya organisasi. Pimpinan yang memberikan tanggungjawab, kepercayaan, memaparkan rencana perusahaan, memberikan arahan, dan mendelegasikan tugas sesuai keahlian karyawan akan membuat karyawan memiliki kebiasaan saling bekerjasama untuk mencapai tujuan. Kepemimpinan yang baik menjadikan karyawan bertanggungjawab, memiliki kepercayaan dan kebiasaan menyelesaikan tugas dengan cepat dan tepat (Herminingsih, 2011; Nurwati, Nimran, Surachman, 2012).

Kepemimpinan seorang pemimpin dalam sebuah organisasi mempunyai perananan yang sangat penting yang dapat menciptakan sebuah komitmen karyawannya. Pemimpin yang dipandang baik oleh karyawan akan menumbuhkan komitmen karyawan (Athar, 2020). Pelaksana kepemimpinan yaitu pemimpin memegang peran penting dalam pencapaian tujuan suatu organisasi sehingga perlu dikelola agar organisasi dapat bersaing (Qorfianalda \& Wulandari, 2021).
Budaya organisasi dan komitmen merupakan hal penting bagi organisasi sehingga perlu dipertahankan atau ditingkatkan. Upaya meningkatkan nilai dan kebiasaan yang baik dan niat sungguh-sungguh melakukan yang terbaik dapat dilakukan oleh pimpinan dengan menerapkan kepemimpinan yang memberikan tanggung jawab dan kepercayaan kepada karyawan untuk menyelesaikan pekerjaan dan memberi kesempatan karyawan untuk memaparkan rencana dalam upaya mencapai tujuan perusahaan. Penelitian ini memiliki arti penting dimana berupaya menempatkan budaya organisasi dan komitmen sebagai kebaruan yaitu memediasi kepemimpinan terhadap kinerja karyawan.

\section{METODOLOGI PENELITIAN}

\section{Pengembangan Model}

\section{Kinerja}

Hasil yang dicapai oleh pegawai merupakan gambaran kinerja pegawai (Andayani \& Tirtayasa, 2019). Kinerja tergambar dari kemampuan karyawan menyelesaikan pekerjaan sesuai target, sesuai dengan standar perusahaan dan hasil kerja karyawan tidak mendapatkan komplain. Kinerja karyawan juga tergambar dari kesesuain hasil dengan target dan standar, berkualitas dan tepat waktu (Mathis \& Jackson, 2011)

\section{Kepemimpinan, Budaya Organisasi, Kinerja}

Setiap organisasi membutuhkan seorang pemimpin yang mampu mampu memimpin organisasinya mencapai suatu tujuan tertentu. Kepemimpinan yang baik mampu memberikan tanggung jawab dan kepercayaan kepada karyawan, mampu memaparkan rencana tujuan perusahaan, memberikan bimbingan, arahan, dan motivasi. Hal ini akan mempengaruhi nilai-nilai yang dianut dalam sebuah organisasi (Andayani, 2019). Pimpinan yang memberikan tanggung jawab dan 
kepercayaan kepada karyawan untuk menyelesaikan pekerjaan akan mendorong karyawan memiliki kebiasaan bekerja dengan menekankan hasil yang maksimal dalam bekerja. Dengan kebiasaan baik yang terjadi di organisasi akan mendorong perusahaan mencapai tujuan yang diinginkan (Mustikaningsih \& Handayani, 2014). Kebiasaan kerjasama tim untuk mencapai tujuan membuat karyawan bekerja sesuai target. Dengan demikian kepemimpinan yang baik akan meningkatkan budaya organisasi yang pada akhirnya meningkatkan kinerja.

H1: kepemimpinan berpengaruh terhadap budaya

H2: budaya berpegaruh terhadap kinerja

H3: kepemimpinan berpengaruh terhadap kinerja melalui budaya

\section{Kepemimpinan, Komitmen, Kinerja}

Salah satu faktor yang harus diperhatikan dalam organisasi untuk meningkatkan kerja karyawan adalah kepemimpinan. Seorang pemimpin dalam sebuah organisasi mempunyai perananan yang sangat penting yang dapat menciptakan sebuah komitmen karyawannya. Pemimpin yang dipandang baik oleh karyawan akan menumbuhkan komitmen karyawan (Athar, 2020). Bimbingan, arahan, dan dorongan dari seorang pemimpin dengan mendelegasikan tugas akan membuat karyawan ingin menumbuhkan rasa bangga dan bahagia dalam bekerja sehingga karyawan berupaya semaksimal mungkin memberikan yang terbaik bagi perusahaan. Tumbuhnya upaya untuk memberikan yang terbaik membuat karyawan dapat menyelesaikan setiap tugas yang menjadi tanggung jawabnya. Komitmen membuat karyawan meningkat kinerjanya (Frimayasa \& Lawu, 2020). Dengan demikian kepemimpinan yang baik akan meningkatkan komitmen yang pada akhirnya meningkatkan kinerja.

H4: kepemimpinan berpengaruh terhadap komitmen

H5: komitmen berpengaruh terhadap kinerja

H6: kepemimpinan berpengaruh terhadap kinerja melalui komitmen.

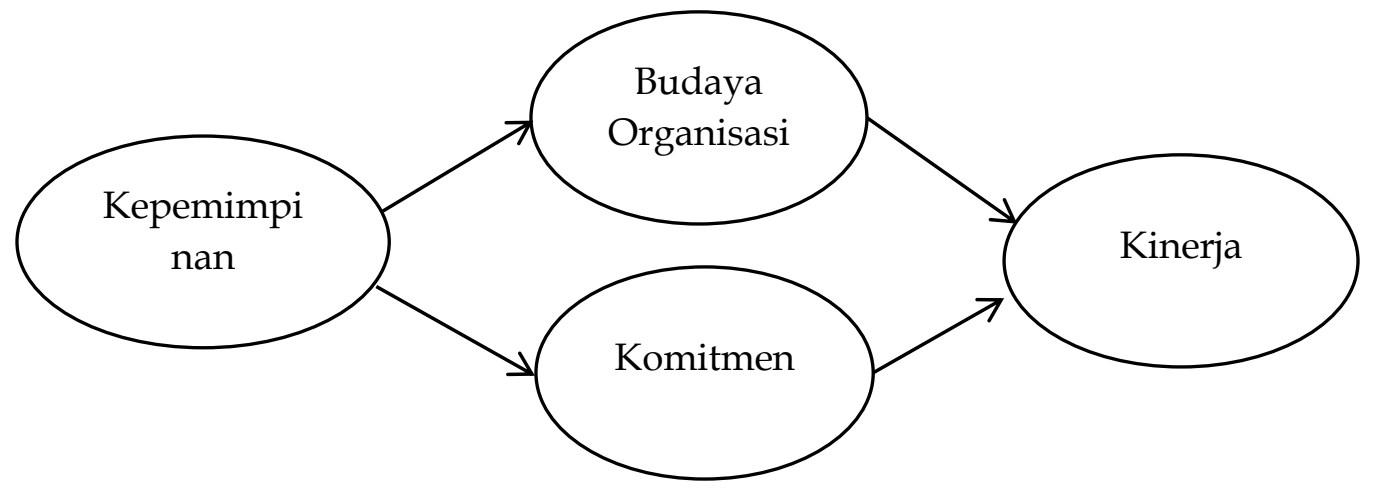

Gambar 1. Desain Penelitian

\section{Pengumpulan Data}

Instrumen penelitian dalam bentuk kuesioner dibagikan kepada 50 karyawan aktif di Cikarang sebagai sampel (Mulyanto \& Wulandari, 2010). Penyebaran memanfaatkan google form yang disebar melaui Whatsapp Grup.

\section{Metode Analisis}

Analisis kuantitatif model struktural merupakan metode yang digunakan. Pengolahan data menggunakan SmartPLS. Loading outer dengan nilai kritias 0,7 digunakan untuk memastikan bahwa instrumen yang digunakan valid sedangkan untuk memastikan variabel 
telah reliabel digunakan Alpha Cronbach's dengan nilai kritis $>0,7$ dan composite reliability dengan nilai kritis $>0,8$. Model dikatakan layak jika laten endogenous memiliki R2 lebih dari 0,2. Pengaruh antar variabel signifikan jika $p$-value kurang dari 0,05 .

Table 1. Pengukuran Variabel

\begin{tabular}{|c|c|c|}
\hline $\begin{array}{l}\text { Variabel/ } \\
\text { Konsep }\end{array}$ & Indikator & Skala \\
\hline $\begin{array}{l}\text { Kepemimpinan } \\
\text { (Siagian, 2010) }\end{array}$ & $\begin{array}{l}\text { Memberikan tanggung jawab dan kepercayaan } \\
\text { Memaparkan rencana mencapai tujuan } \\
\text { Memberikan bimbingan, arahan, dan motivasi } \\
\text { Mendelegasikan tugas }\end{array}$ & $1-5$ \\
\hline $\begin{array}{l}\text { Budaya } \\
\text { organisasi } \\
\text { (Robbins dan } \\
\text { Judge, 2015) }\end{array}$ & $\begin{array}{l}\text { Menekankan hasil maksimal } \\
\text { Menekankan kerjasama tim } \\
\text { Menekankan penyelesaian pekerjaan tepat dan cepat } \\
\text { Nilai perubahan }\end{array}$ & $1-5$ \\
\hline $\begin{array}{l}\text { Komitmen } \\
\text { (Panggabean, } \\
\text { 2011) }\end{array}$ & $\begin{array}{l}\text { Tidak ingin pindah } \\
\text { Rasa memiliki perusahaan } \\
\text { Memberikan yang terbaik } \\
\text { Membanggakan perusahaan }\end{array}$ & $1-5$ \\
\hline $\begin{array}{l}\text { Kinerja (Mathis } \\
\text { \& Jackson, } \\
\text { 2011) }\end{array}$ & $\begin{array}{l}\text { Menyelesaikan pekerjaan sesuai target } \\
\text { Hasil kerja sesuai standar perusahaan } \\
\text { Hasil kerja tidak mendapatkan komplain } \\
\text { Menyelesaikan pekerjaan tepat waktu }\end{array}$ & $1-5$ \\
\hline
\end{tabular}

Sumber: Rangkuman teori, 2021

\section{HASIL}

Tabel 2 memperlihatkan dominasi laki-laki sebagai reponden. Tabel 3 memperlihatkan tiap variabel telah valid (outer loading lebh dari 0,7) dan reliabel (Cronbach Alpha lebih dari 0,7 dan Compositie Reliability lebih dari 0,80). Model telah fit dengan R square lebih besar dari 0,2 yaitu budaya organisasi 0,587 (kuat), kinerja 0,669 (kuat) dan komitmen 0,416 (substansial) sebagaimana tabel 4 .

Tabel 5 menunjukan bahwa: 1) Kepemimpinan positif signifikan terhadap budaya organisasi; 2) Kepemimpinan positif signifikan terhadap komitmen; 3) Budaya organisasi tidak signifikan terhadap kinerja; 4) Komitmen positif signifikan terhadap kinerja.

Tabel 2. Responden

\begin{tabular}{llll}
\hline & Jenis Kelamin & Jumlah & Persen \\
\hline - Perempuan & 19 & 31,7 \\
- Laki-laki & 41 & 68,3 \\
\hline
\end{tabular}


Tabel 3. Outer Model

\begin{tabular}{|c|c|c|c|c|}
\hline Variabel/Indikator & $\begin{array}{l}\text { Outer } \\
\text { Loading }\end{array}$ & $\begin{array}{l}\text { Cromba } \\
\text { h Alpha }\end{array}$ & $\begin{array}{l}\text { Composite } \\
\text { Reliability }\end{array}$ & Kesimpulan \\
\hline Kepemimpinan & & 0,937 & 0,955 & Reliabel \\
\hline - $\quad$ Memberikan kepercayaan & 0,901 & & & Valid \\
\hline - $\quad$ Memaparkan rencana kerja & 0,937 & & & Valid \\
\hline - Membimbing dan mengarahkan & 0,931 & & & Valid \\
\hline - $\quad$ Mendelegasikan tugas & 0,901 & & & Valid \\
\hline Budaya Organisasi & & 0,869 & 0,911 & Reliabel \\
\hline - $\quad$ Menekankan hasil yang maksimal & 0,877 & & & Valid \\
\hline - Menekankan kerjasama tim & 0,846 & & & Valid \\
\hline - Menekankan ketepatan dan ketepatan & 0,822 & & & Valid \\
\hline - Menyesuaikan dengan perubahan & 0,843 & & & Valid \\
\hline Komitmen & & 0,82 & 0,882 & Reliabel \\
\hline - $\quad$ Tidak ingin pindah pekerjaan & 0,718 & & & Valid \\
\hline - $\quad$ Rasa memiliki & 0,809 & & & Valid \\
\hline - $\quad$ Memberikan yang terbaik & 0,873 & & & Valid \\
\hline - Membanggakan organisasi & 0,823 & & & Valid \\
\hline Kinerja & & 0,875 & 0,915 & Reliabel \\
\hline - $\quad$ Menyelesaikan pekerjaan sesuai target & 0,749 & & & Valid \\
\hline - Hasil sesuai standar perusahaan & 0,887 & & & Valid \\
\hline - Hasil kerja tidak mendapatkan komplain & 0,855 & & & Valid \\
\hline - Menyelesaikan pekerjaan tepat waktu & 0,919 & & & Valid \\
\hline
\end{tabular}

Sumber: Hasil Pengolahan, 2021

Tabel 4. Uji Model

\begin{tabular}{llll}
\hline Endogenous Variabel & Nilai kritis & Hasil & Evaluasi model \\
\hline $\mathrm{R}^{2}$ & & & \\
$-\quad$ Budaya Organisasi & $\geq 0,20$ & 0,587 & Fit \\
$-\quad$ Komitmen & $\geq 0,20$ & 0,416 & Fit \\
- Kinerja & $\geq 0,20$ & 0,699 & Fit \\
\hline
\end{tabular}

Sumber: Hasil Pengolahan,, 2021 


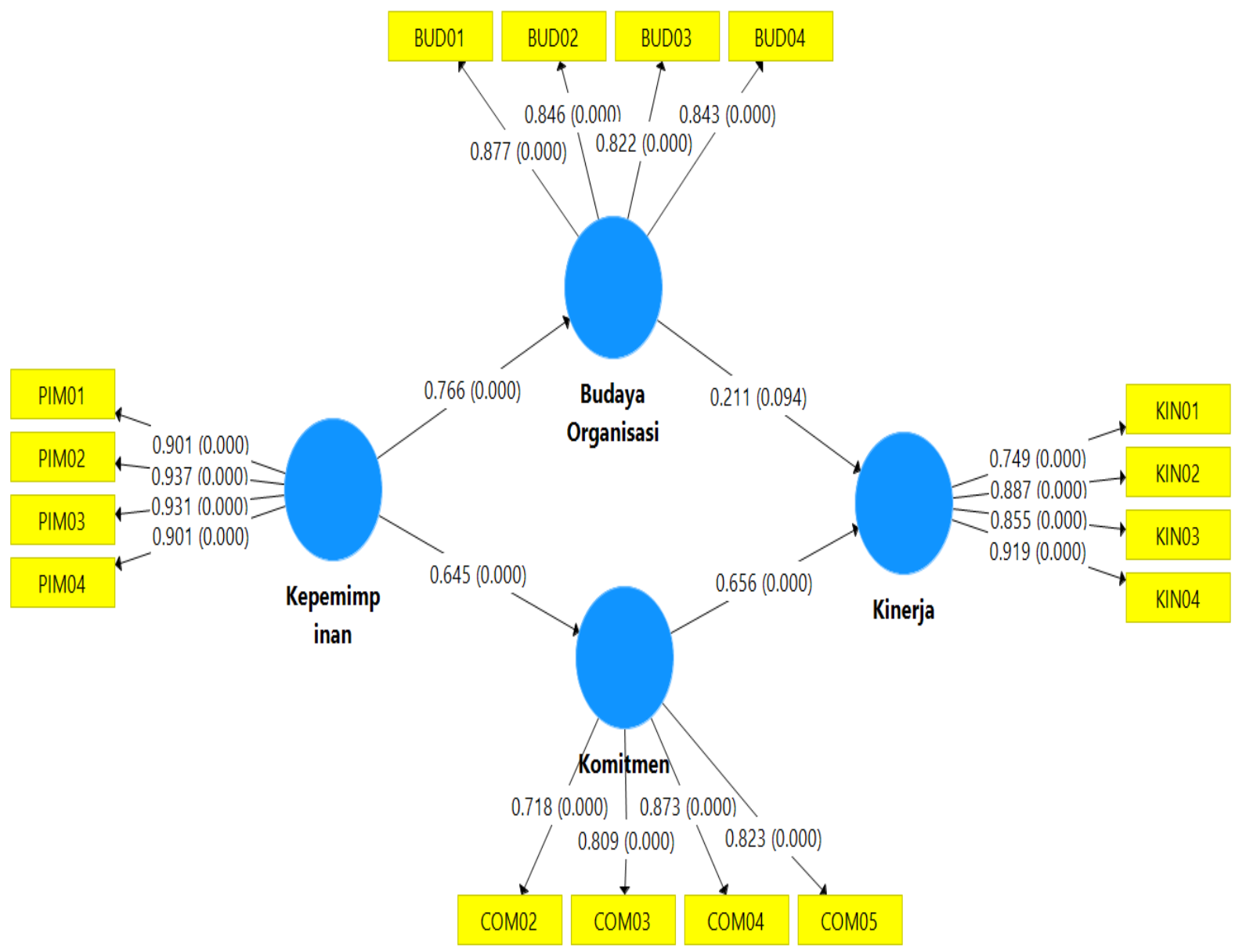

Gambar 2. Model

Tabel 5. Estimasi

\begin{tabular}{|c|c|c|c|c|}
\hline Alur & Kategori & Koefisien & P-Value & Kesimpulan \\
\hline Kepemimpinan $\rightarrow$ Budaya Organisasi & Langsung & 0,766 & 0,000 & Signifikan \\
\hline Kepemimpinan $\rightarrow$ Komitmen & Langsung & 0,645 & 0,000 & Signifikan \\
\hline Budaya Organisasi $\rightarrow$ Kinerja & Langsung & 0,211 & 0,094 & $\begin{array}{l}\text { Tidak } \\
\text { Signifikan }\end{array}$ \\
\hline Komitmen $\rightarrow$ Kinerja & Langsung & 0,656 & 0,000 & Signifikan \\
\hline $\begin{array}{l}\text { Kepemimpinan } \rightarrow \text { Budaya Organisasi } \\
\rightarrow \text { Kinerja }\end{array}$ & $\begin{array}{l}\text { Tidak } \\
\text { Langsung }\end{array}$ & 0,099 & 0,105 & $\begin{array}{l}\text { Tidak } \\
\text { Signifikan }\end{array}$ \\
\hline $\begin{array}{l}\text { Kepemimpinan } \rightarrow \text { Komitmen } \rightarrow \\
\text { Kinerja }\end{array}$ & $\begin{array}{l}\text { Tidak } \\
\text { Langsung }\end{array}$ & 0,423 & 0,000 & Signifikan \\
\hline
\end{tabular}

Sumber: Data penelitian yang diolah, 2021 


\section{PEMBAHASAN}

\section{Kepemimpinan terhadap budaya organisasi}

Kepemimpinan dalam penelitian ini mempengaruhi budaya organisasi dengan arah positif. Tanggung jawab yang diberikan pimpinan kepada karyawannya akan menumbuhkan kebiasaan karyawan untuk meriah hasil yang maksimal dalam bekerja. Rencana kerja yang dipaparkan oleh pimpinan dan adanya pendelegasian tugas akan mendorong kerjasama sebagai sebuah nilai budaya organisasi.

Hasil penelitian ini memperkuat temuan sebelumnya (Herminingsih, 2011; Nurwati, Nimran, Surachman, 2012) dimana kepemimpinan yang baik menjadikan karyawan menjunjung budaya organisasi. Hal ini memberikan masukan bagi organisasi agar kepemimpinan perlu diperkuat agar budaya organisasi berjalan semakin baik. Upaya meningkatkan kepemimpinan antara lain dengan cara memberikan tanggungjawab penuh kepada karyawan, memaparkan rencana perusahaan dimasa yang akan datang, memberikan arahan dengan detail kepada karyawannya, dan mendelegasikan tugas sesuai keahlian karyawan.

\section{Kepemimpinan terhadap komitmen}

Kepemimpinan dalam penelitian ini mempengaruhi komitmen karyawan secara positif. Pimpinan yang baik akan menjadikan karyawan betah dan ingin terus bertahan di organisasi. Bimbingan, arahan dan dorongan yang baik dari pemimpin organisasi membuat karyawan lebih mempunyai rasa memiliki, akan memberikan kemampuan terbaiknya dan merasa bangga dalam melaksanakan pekerjaannya.

Hasil penelitian ini sesuai dengan yang pernah ada (Purnomo, 2018) dimana kepemimpinan yang baik berpengaruh positif terhadap komitmen karyawan. Temuan ini sekaligus penelitian ini juga menjawab penelitian sebelumnya yang menyatakan bahwa kepemimpinan tidak berpengaruh positif terhadap komitmen (Ghoniyah \& Masurip, 2011). Oleh karena itu, kepemimpinan yang baik perlu diupayakan yaitu dengan mendorong pemimpin organisasi untuk memberikan kepercayaan, membimbing, mengarahkan dan memotivasi serta mendelegasikan tugas kepada karyawannya.

\section{Budaya organisasi terhadap kinerja}

Budaya organisasi dalam penelitian ini tidak berpengaruh terhadap kinerja karyawan. Kebiasaan-kebiasaan yang ada di organisasi seperti kerjasama tim, menyelesaikan tugas dengan cepat dan penyesuaian perubahan sistem tidak menjadikan karyawan mampu meningkatkan hasil tugas secara kuantitas dan kualitas.

Tidak adanya pengaruh budaya terhadap kinerja pada penelitian ini berbeda dengan sebelumnya (Kardinah Indrianna Meutia, 2019) yang justru menghasilkan temuan bahwa budaya organisasi berpengaruh terhadap kinerja. Temuan ini justru menjadi celah untuk ditelaah kembali pada penelitian selanjut karena bagaimanapun juga budaya organisasi tetap penting bagi perusahaan

\section{Komitmen terhadap kinerja}

Temuan selanjutnya adalah adanya pengaruh positif komitmen terhadap kinerja secara. Karyawan yang tidak punya hasrat untuk pindah, memiliki rasa memiliki, mampu memberikan yang terbaik untuk perusahaan dan merasakan bahagia dalam bekerja mampu meningkatkan kinerja karyawan.

Penelitian ini sesuai dengan yang sebelumnya (Putra, 2015) yang menyatakan bahwa komitmen positif dalam mempengaruhi kinerja. Niatan yang sungguh-sungguh untuk tidak pindah ke organisasi lain merupakan bekal yang mendorong pegawai untuk mencapai hasil yang terbaik. Oleh karena itu memupuk kebanggaan agar karyawan tergerak dengan sungguh-sungguh memberikan 
yang terbaik perlu menjadi program organisasi.

\section{Kepemimpinan terhadap kinerja melalui budaya organisasi}

Budaya organisasi pada penelitian ini tidak memediasi kepemimpinan terhadap kinerja. Kepemimpinan yang mampu meningkatkan budaya organisasi, tetapi budaya yang telah terbentuk tidak mampu meningkatkan kinerja karyawan.

Budaya organisasi dipengaruhi kepemimpinan, sejalan dengan temuan sebelumnya (Herminingsih, 2011; Nurwati, Nimran, Surachman, 2012), tetapi tidak adanya pengaruh budaya terhadap kinerja berbeda dengan temuan sebelumnya (Mustikaningsih \& Handayani, 2014) meskipun sejalan dengan temuan lainnya (Lina, 2014).

\section{Pengaruh kepemimpinan terhadap kinerja melalui komitmen}

Komitmen pada penelitian ini memediasi kepemimpinan terhadap kinerja. Pemimpin yang baik mampu meningkatkan membangkitkan rasa memiliki yang pada akhirnya akan meningkatkan hasil kerja.

Penelitian ini menguatkan temuan sebelumnya dimana (Purnomo, 2018) dimana kepercayaan yang diberikan pimpinan akan menumbuhan hasrat karyawan untuk memberikan yang terpabi (Andayani \& Soehari, 2019) dan hasrat tersebut mampu meningkatkan kinerja secara kuantitas dan kualitas. Hasil ini menjawab penelitian sebelumnya (Saputri \& Andayani, 2018), bahwa tidak adanya pengaruh kepemimpinan terhadap kinerja karena kepemimpinan tidak secara langsung mempengaruhi kinerja melainkan melalui komitmen.

\section{KESIMPULAN}

Kepemimpinan mempengaruhi budaya organisasi tetapi budaya tidak mempengaruhi kinerja sehingga budaya organisasi tidak memediasi kepemimpinan terhadap kinerja. Kepemimpinan mempengaruhi komitmen dan komitmen mempengaruhi kinerja sehingga komitmen memediasi kepemimpinan terhadap kinerja.

Penelitian berikutnya berpeluang membangun budaya organisasi yang tidak mempengaruhi kinerja. Penelitian menggunakan pengukuran lebih rinci atau sangat disarankan.

\section{DAFTAR PUSTAKA}

Alwafi, F., \& Magnadi, R. H. (2016). Pengaruh Persepsi Keamanan, Kemudahan Bertransaksi, Kepercayaan Terhadap Toko dan Pengalaman Berbelanja Terhadap Minat Beli Secara Online pada Situs Jual Beli Tokopedia.com. Diponegoro Hournal of Management, 5(2), 115.

Andayani, A., \& Soehari, T. D. (2019). Pengaruh Budaya Organisasi, Komitmen Organisasi Dan Gaya Kepemimpinan Terhadap Kinerja Karyawan. Akademika Jurnal teknologi Pendidikan, Vol 8 No. 2, 129-145.

Andayani, I., \& Tirtayasa, S. (2019). Pengaruh Kepemimpinan, Budaya Organisasi, Dan Motivasi Terhadap Kinerja Pegawai. Jurnal Ilmiah Magister Manajemen, Vol 2, No. 1(ISSN 2623-2634), 45-54.

Athar, H. S. (2020). Dampak Gaya Kepemimpinan, Komitmen Organisasi, Dan Kepuasan Kerja Terhadap Kinerja Pegawai Pada Dinas Sosial Kabupaten Lombok Timur. Jurnal RisetManajemen dan Bisnis (JRMB), Vol. 5, No 2(P-ISSN 2527-7502 E-ISSN 2581-2165), 2940. 
Frimayasa, A., \& Lawu, S. H. (2020). Pengaruh Komitmen Organisasi Dan Human Capital Terhadap Kinerja Pada Karyawan Pt. Frisian Flag. Equilibrium, Vol 9 No. 1(eISSN 26849313), 36-47.

Ghoniyah, N., \& Masurip. (2011). Peningkatan Kinerja Karyawan Melalui Kepemimpinan, Lingkungan Kerja Dan Komitmen. Jurnal Dinamika Manajemen, Vol. 2, No. 2(ISSN 23375434 ), 118-129.

Herminingsih, A. (2011). Pengaruh Kepemimpinan Transformal terhadap Budaya Organisasi. Manajemen Sumber Daya Manusia, Vol. 5 No.1(ISSN (E) 2597-4823), 22-37.

Kardinah Indrianna Meutia, C. H. (2019). Pengaruh Budaya Organisasi Dan Komitmen Organisasi Terhadap Kinerja Karyawan. Jurnal Riset Manajemen dan Bisnis (JRMB), Vol 4(P-ISSN 2527-7502 E-ISSN 2581-2165), 119-126.

Kinasih, B. S., \& Albari. (2012). Pengaruh Persepsi Keamanan dan Privasi Terhadap Kepuasan dan Kepercayaan Konsumen Online. Jurnal Siasat Bisnis, 16(1), 25-38.

Lina, D. (2014). Analisis Pengaruh Kepemimpinan Dan Budaya Organisasi Terhadap Kinerja Pegawai Dengan Sistem Reward Sebagai Variabel Moderating. Jurnal Riset Akuntansi Dan Bisnis , Vol 14 No . 1(ISSN 2623-2650), 77-97.

Mathis, R., \& Jackson, J. (2012). Manajemen Sumber Daya Manusia. Jakarta: Salemba Empat.

Mulyanto, H., \& Wulandari, A. (2010). Penelitian: Metode \& Analisis. Semarang: CV Agung.

Mustikaningsih, Y. S., \& Handayani, R. (2014). Pengaruh Gaya Kepemimpinan, Budaya Organisasi, Komitmen Organisasi Dan Remunerasi Terhadap Kinerja Karyawan. Media Ekonomi Dan Manajemen, Vol 29 No. 1(ISSN : 085-1442), 44-58.

Nurwati, U. N. (2012). Pengaruh Kepemimpinan terhadap Budaya Organisasi, Komitmen Kerja, Perilaku Kerja dan Kinerja Pegawai. Jurnal Aplikasi Manjemen, Vol 10. No. 1 ( ISSN 1693-5241 ), 1-11.

Pangabean, M. (2011). Manajemen Sumber Daya Manusia. Jakarta: Ghalia Indonesia.

Poerwaningrum, H. E., \& Sudirjo, F. (2016). Pengaruh Kepemimpinan, Budaya Organisasi, Komitmen Organisasi Dan Kepuasan Kerja Terhadap Kinerja. Jurnal Ilmiah UNTAG Semarang, Vol. 5 No. 1(ISSN : 2302-2752,), 1-12.

Pratama, S. (2017). Pengaruh Budaya Organisasi Terhadap Kinerja Karyawan Pada PT Intan Bara Utama Samarinda. eJournal Administrasi Bisnis, Vol 5 No 4 ( ISSN 2355-5408 ), 1-15.

Purnomo, E. (2018). Pengaruh Kepemimpinan terhadap Komitmen Organisasi. sosio e-kons, Vol 10. No 10 ( ISSN 2502-5449), 28-38.

Putra, S. W. (2015). Pengaruh Komitmen Organisasi, Budaya Organisasi, Gaya Kepemimpinan Dan Lingkungan Terhadap Kinerja Karyawan Pada Industri Kecil. Jurnal Ekonomi Modernisasi, Vol 11 No. 7(ISSN : 0216-373X), 62-77.

Qorfianalda, S., \& Wulandari, A. (2021). Budaya Organisasi Terhadap Kinerja Dimediasi Kepuasan dan Loyalitas Kerja Karyawan. EKOMABIS: Jurnal Ekonomi Manajemen Bisnis, Vol 2 No. 2 (e-ISSN 2716-0238), 157-168 .

Saputri, R., \& Andayani, N. R. (2018). Pengaruh Kepemimpinan Dan Motivasi Kerja Terhadap Kinerja Pegawai Pada Departemen Production Di Pt Cladtek Bi-Metal Manufacturing Batam. Journal of Applied Business Administration, Vol 2, No 2 ( e-ISSN: 2548-9909 ), 307316. 
Syamsir, \& Hidayat, R. (2020). Pengaruh komitmen organisasi dan kepuasan kerja terhadap intention turnover pegawai. Insight Management Journal, Vol 1 No.1(ISSN 2774-1737), 15 . 